\title{
Assessing the predatory activity of Arthrobotrys oligosporus strain C-2197 as biocontrol of the root-knot nematode Meloidogyne spp.
}

\author{
Adela Quevedo ${ }^{1}$, Marcos Vera-Morales ${ }^{1}$, Fernando Espinoza-Lozano ${ }^{1}$, Rafael F. Castañeda-Ruiz ${ }^{3}$, Daynet Sosa ${ }^{1,2}$, Freddy Magdama ${ }^{1,2^{*}}$
}

DOl. 10.21931/RB/2021.06.01.22

Abstract: The root-knot nematode, Meloidogyne spp., is an endoparasite that infects plants' root system and causes yield losses in several important crops. Meloidogyne is one of the most devastating pests, so searching for effective biological agents is needed to mitigate its damage. In this study, the predatory activity of Arthrobotrys oligosporus Fresen strain C-2197, obtained from a tropical dry forest of Ecuador, was evaluated as a biocontrol alternative for root-knot caused by Meloidogyne spp. Our results showed that A. oligosporus C-2197 has predatory activity against juvenile nematodes, $72.31 \%$, and $79 \%$ efficacy, for in vitro and greenhouse conditions. Besides, the studied strain showed growth-promoting activity, increasing leaf and root area of inoculated plants. Growth promoting activity was also observed in field tests. The present study validates the potential use of $A$. oligosporus as a biocontrol of Meloidogyne spp. in tomato production systems under greenhouse. It also presents useful information on the use of different cultivation media and substrates for massive A. oligosporus spore concentrates.

Key words: Arthrobotrys oligosporus, Meloidogyne, biocontrol, root system.

\section{Introduction}

Phytoparasitic nematodes are considered one of the greatest threats to agriculture worldwide, with estimated losses exceeding $\$ 100$ billion per year ${ }^{1}$. Nematodes of the genus Meloidogyne are the essential phytoparasitic pathogens from an economic and scientific standpoint ${ }^{2,3}$ as they can affect more than 2,000 species of plants ${ }^{4}$, including cultivars of enormous food importance ${ }^{5,6}$. Previous studies have described 100 species belonging to the genus Meloidogyne ${ }^{7}$, of which M. incognita, M. javanica, M. hapla and $M$. arenaria have been reported in Ecuador ${ }^{8,9}$, causing damage on more than $25 \%$ of the horticultural yield production of the country ${ }^{10}$.

The management of Meloidogyne spp. is cumbersome as different reproductive strategies allow this species to adapt quickly to a wide range of temperatures and environments ${ }^{11}$. This group's high diversity and the intensive crop production practices exacerbate their incidence and facilitate their dispersal across fields ${ }^{12,13}$. These nematodes attack exposed roots by modifying their structure and growth, causing the formation of giant cells due to nutrient uptake ${ }^{14}$, which translates, sometimes in a short time, into low yield ${ }^{15}$.

With the growing advance of agriculture, chemical pesticides were developed ${ }^{16}$ to overcome this problem. However, their frequent use has caused several side effects, affecting soil health by reducing biological activity ${ }^{17}$. Another concern about pesticides is the risk they pose to human health, including infections, malignancies, lung inflammation, and others ${ }^{18,19}$. New regulations regarding the use of these chemicals continue to be enforced by international agencies to help alleviate the negative effect of their use in farmers' lives ${ }^{20}$. In this regard, the search for alternatives to mitigate the effect of nematodes less environmentally damaging and safer for human use is highly encouraged. Among those, biological control agents are a feasible option for pest management ${ }^{21}$. Examples clearly have shown that controlling agents can reduce root-knot nematode populations and damage levels ${ }^{22}$ up to $45 \%$ compared to un- controlled conditions ${ }^{23}$.

Within the gamma of antagonistic microorganisms, nematophagous fungi outstand this activity on trapping and devouring nematodes using specialized structures that allow them to penetrate the cuticle's nematode to grow inside, utterly killing them ${ }^{24,25}$. Although their habitat is the soil, these fungi can change their lifestyle from saprophytic to pathogenic once they contact the nematode ${ }^{26,27}$. Some reported modes of action include the development of specialized traps such as constriction rings, non-constriction rings, adhesive knobs, adhesive nets, and adhesive columns ${ }^{28,29}$. Some more specialized species, such as Arthrobotrys oligosporus, can even produce volatile compounds to attracts their prey until the mycelial traps are ready to function correctly, which in some cases, can take more than twelve hours to form ${ }^{30}$.

A. oligosporus grows in soil, around roots, and animal feces $^{31}$, but found particularly in nematode-infested soils ${ }^{32}$. This fungus has significantly reduced pathogen populations ${ }^{33}$. It has been extensively studied under laboratory and semi-controlled and open field conditions in tomato production ${ }^{34,35}$. Thus, the search for new strains of $A$. oligosporus with similar or better nematophagous activity can help develop new products for controlling Meloidogyne spp. in Ecuador to improve tomato's local production. This study's objective was to evaluate the predatory activity of $A$. oligosporus strain C-2197 against the root-knot nematode Meloidogyne spp.

\section{Methods}

A. oligosporus strain C-2197 was isolated from decomposing leaves collected at the site of Santa Rosa, El Oro province (Ecuador), in a forest adjacent to a coffee plantation with limited anthropogenic activity. The samples were collected in plastic bags and taken to the laboratory, where they were placed in humid chambers for fifteen days ${ }^{36,37}$. After the isolation and

1 Escuela Superior Politécnica del Litoral, ESPOL, Centro de Investigaciones Biotecnológicas del Ecuador, Guayaquil, Ecuador.

2Escuela Superior Politécnica del Litoral, ESPOL, Facultad de Ciencias de la Vida, Guayaquil, Ecuador.

${ }^{3}$ Instituto de Investigaciones Fundamentales en Agricultura (INIFAT), Tropical 'Alejandro de Humboldt', OSDE, Grupo Agrícola, C. Habana, Cuba. 
identification of this fungus using taxonomic keys, monoconidial colonies were obtained for later use. A. oligosporus C-2197 was deposited in the Microorganism Culture Collection of the Biotechnology Research Centre of Ecuador (CIBE) with the code CCMCIBE-H481. To maintain the predatory activity of our strain, the colonies were kept in cornmeal agar media $(\mathrm{CMA})^{38}$.

For this study, the initial population of Meloidogyne spp. was obtained from tomato plants of the Granja Agricola Experimental (GEA) located in the Escuela Superior Politécnica del Litoral (ESPOL). To maintain the nematode population, hybrid ABM-135 tomato plants were infected and kept in the greenhouse.

The growth of $A$. oligosporus C-2197 was evaluated in six different culture media: water agar, v-8 juice agar, corn meal agar (CMA), carrot agar, cornmeal + carrot agar, and oat agar. Radial growth was measured every 24 hours up to eight days. During this time, the Petri dishes were incubated at $280 \mathrm{C}$. Then, spore counts were performed in solutions obtained after scraping the colonies' surfaces with $5 \mathrm{ml}$ of sterile water. The number of spores was calculated using a Neubauer camera. The experiment included five replicates per treatment.

To evaluate the predatory effect of A. oligosporus C-2197 under laboratory conditions, ten egg masses of Meloidogyne spp. were placed in Petri dishes with water agar. After 24 hours from the juvenile nematodes' appearance, $1 \mathrm{ml}$ of spore solution of $A$. oligosporus C-2197, previously adjusted to $1 \times 10^{6} \mathrm{cfu} / \mathrm{ml}$, was poured into each Petri dish. This trial included the evaluation of ten replicas (Petri dishes) placed at ambient temperature. After 24 hours of incubation, the number of live, dead, static, parasitized, and non-parasitized nematodes were evaluated.

To assess the effect of $A$. oligosporus C-2197 under greenhouse conditions, three-week old ABM-135 hybrid tomato plants were inoculated with ten egg masses of Meloidogyne spp. four days before placing the spore suspensions $\left(1 \times 10^{6} \mathrm{cfu} /\right.$ $\mathrm{ml}$ ) of the biocontrol. For this experiment, spore suspensions were obtained from colonies growing on a natural fiber substrate. The experiment was conducted following a completely randomized block design with four plants per treatment with four replicates $(\mathrm{N}=48)$, including $\mathrm{T} 1$ - $A$. oligosporus $(A O L) ; T 2$ - Chemical control (NQ), and T3 - Water (CONTROL). Nematode root infection was evaluated by counting the number of egg masses and determining root-knot damage ${ }^{39}$. Response variables included plant height, stem diameter, fresh and dry weight of the plant, fresh and dry weight of the roots.

Finally, the effect of A. oligosporus C-2197 was also evaluated in small field plots. Tomato plants previously infected with ten egg masses of Meloidogyne spp. and then planted in the field were treated with $1 \mathrm{~L}$ of a spore solution ( $1 \times 10^{6} \mathrm{cfu}$ / $\mathrm{ml}$ ) of A. oligosporus C-2197 sprayed directly on a "Bio-cover" (made of banana fiber woven with straw from rice) (Figure. 1 A-B). The experiment included plants treated with a commercial product and negative control for proper comparison. In total, 10 plants were evaluated per treatment for six weeks following a completely randomized block design. Response variables included plant height, number of flowers and fruits.

\section{Results}

The radial growth experiment showed that $A$. oligosporus C-2197 has a differential growth response in all media evaluated (Figure. 2A). The fungus thoroughly colonized the Petri dishes' surface, in some cases, from the fifth day. Of the six media evaluated, the best results were observed with oatmeal and cornmeal agar + carrot agar, however, no significant differences were found (Figure 2B). Sporulation of A. oligosporus C-2197 was highly increased with significant differences $(p<$ 0.05 ) in v8 juice agar and corn meal agar CMA. Spore count in these treatments was higher than $1 \times 10^{6} \mathrm{cfu} / \mathrm{ml}$ after nine days of mycelium growth. In contrast, the fungus produced fewer spores on water agar and carrot agar (Figure 2C).

The in vitro confrontation test revealed that $A$. oligosporus C-2197 had a control efficiency of $72.31 \%$ over the total number of nematodes exposed to the fungus. This percentage included dead and static nematodes (Figure. 3 A-B).

Control activity against Meloidogyne spp. was also observed in the greenhouse assay. Plants treated with A. oligosporus showed better root development than controls (Figure. 4) and significant differences in nematode egg mass reduction, with an effectiveness of $79 \%$, compared to the negative control (Table 1). The plants' root health treated with $A$. oligosporus also correlated with the increase of plant height at the end of the experiment, which differed significantly from the controls (Figure. 5). Levels of root nematode infestation also differed among treatments. Plants treated with A. oligosporus and the commercial product showed less root-knot damage (values between 0-2) than the control (values 3-4), according to the qualitative scale used.

Field experiments also showed plants treated with $A$. oligosporus had better development $(20 \mathrm{~cm}$ above control plants) (Table 2); however, there were no significant differences regarding the number of flowers and fruits produced by plants on each treatment.
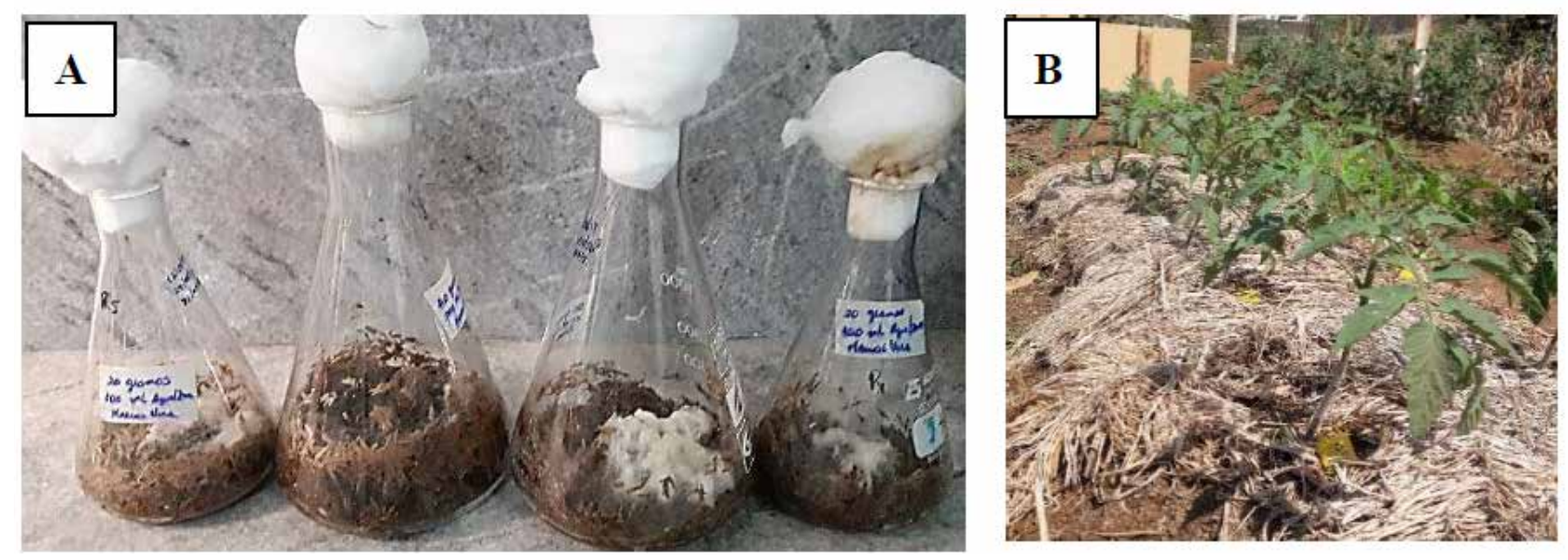

Figure 1. (A) Inoculum production of A. oligosporus C-2197 in flasks under controlled conditions. (B) "Bio-cover" inoculated with A. oligosporus C-2197 surrounding hybrid tomato plants ABM 135 after 2 weeks of transplant in field plots. 
A
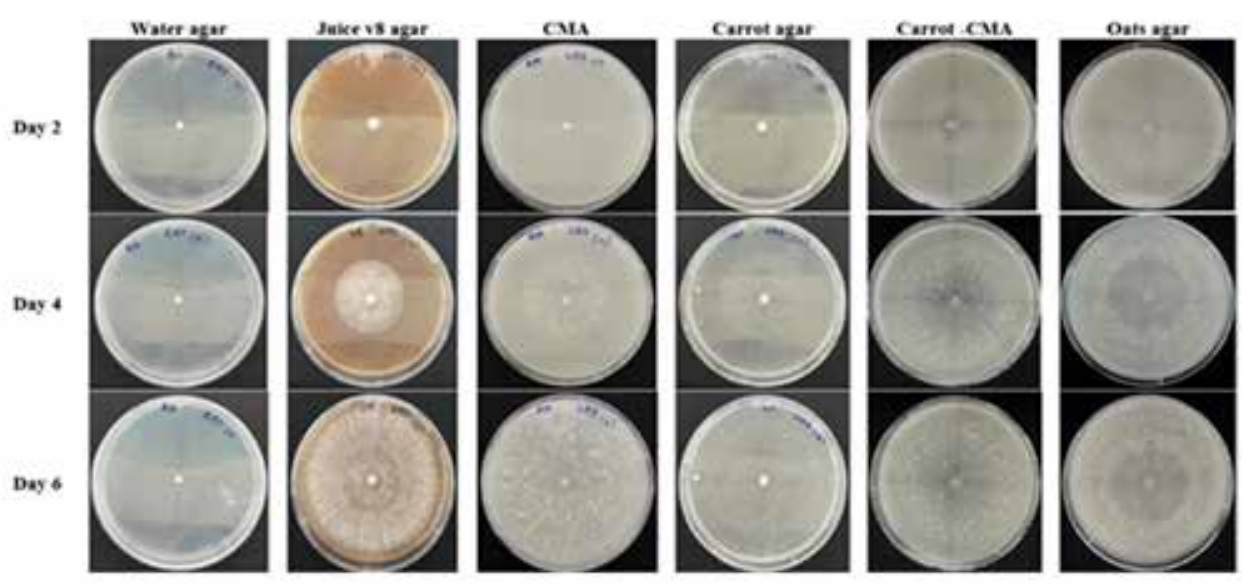

B

C
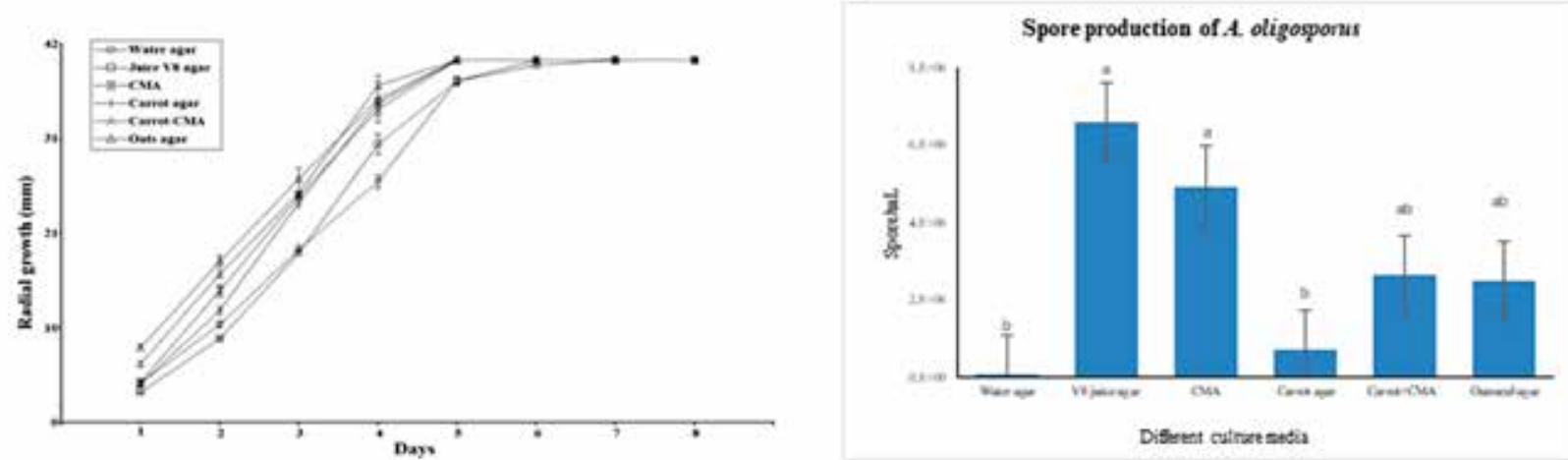

Figure 2. (A) Comparison of the growth of A. oligosporus C-2197 in different media, evaluated on the second, fourth and sixth day. (B) Radial growth of A. oligosporus C-2197 cultivated in six different media cultures: water agar, v-8 juice agar, corn meal agar CMA, carrot agar, cornmeal + carrot agar, and oatmeal agar. (C) Spore production of A. oligosporus C-2197 on different culture media.

A

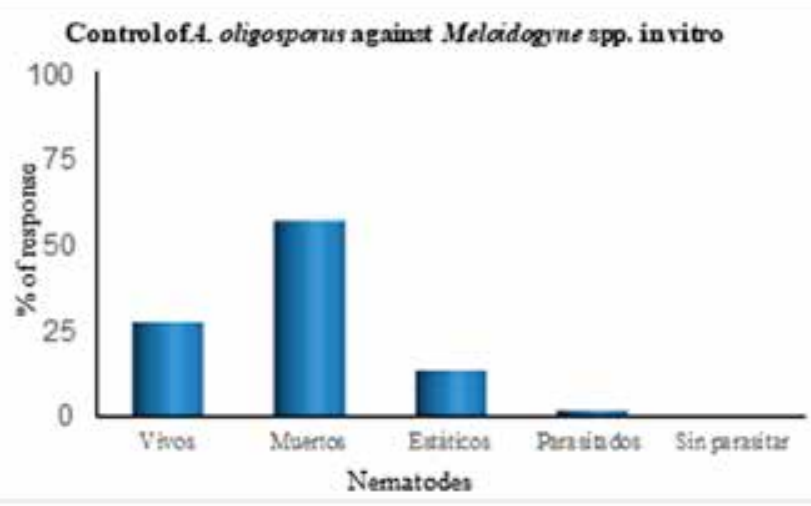

B
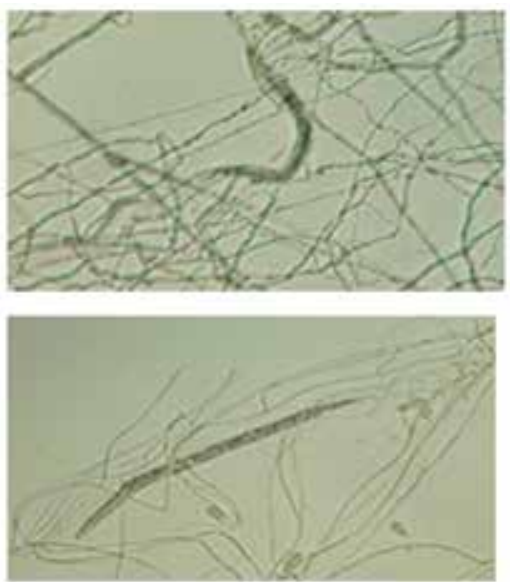

Figure 3. (A) Response percentage of the application of A. oligosporus against the nematode Meloidogyne spp. under in vitro conditions. (B) Nematodes trapped in three-dimensional webs of A. oligosporus C-2197

\begin{tabular}{|c|c|c|c|c|c|c|c|}
\hline \multirow[t]{2}{*}{ Treatment } & \multicolumn{6}{|c|}{ Parameters } & \multirow[b]{2}{*}{$\begin{array}{l}\text { Gall index } \\
(0-10)^{\wedge}\end{array}$} \\
\hline & $\begin{array}{l}\text { Fresh shoot } \\
\text { weight (g) }\end{array}$ & $\begin{array}{l}\text { Dry shoot weight } \\
\text { (g) }\end{array}$ & $\begin{array}{l}\text { Fresh root } \\
\text { weight (g) }\end{array}$ & $\begin{array}{l}\text { Dry root } \\
\text { weight (g) }\end{array}$ & $\begin{array}{l}\text { Root height } \\
\text { (cm) }\end{array}$ & $\begin{array}{l}\text { Numbers of } \\
\text { egg mass/plant }\end{array}$ & \\
\hline $1 \mathrm{AOL}$ & $136,40=6.12^{\AA}$ & $21.73 \pm 0.92^{\lambda}$ & $22.40=1.73 \lambda$ & $2.73=0.19^{\wedge}$ & $42.13=1,78^{\wedge}$ & $23,93 \pm 2,95^{\wedge}$ & $1,0 \pm 0.1^{\mathrm{A}}$ \\
\hline 2NQ & $78,38 \pm 5,93^{\mathrm{B}}$ & $11.06 \pm 0.89^{\mathrm{g}}$ & $15,44 \pm 1.68^{\mathrm{B}}$ & $2,13=0.19^{A B}$ & $38.56=1.72^{A 9}$ & $42,75 \pm 2.86^{\wedge}$ & $1.8 \pm 0.1^{A}$ \\
\hline 3 CONTROL & $68,44 \pm 5,93^{\mathrm{B}}$ & $10,25 \pm 0,89^{5}$ & $16,38 \pm 1,68^{B}$ & $1,88=0.19^{b}$ & $37,38 \pm 1,72^{8}$ & $113,63 \pm 2,86^{\mathrm{B}}$ & $3,8 \pm 0.2^{B}$ \\
\hline
\end{tabular}

Table 1. Effect of A. oligosporus on tomato plants inoculated with the root-knot nematode Meloidogyne spp. in greenhouse conditions. 


\begin{tabular}{|c|c|c|c|c|c|c|c|}
\hline \multirow{3}{*}{ 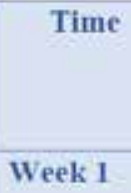 } & \multirow{3}{*}{$\begin{array}{l}\text { Treatment } \\
\text { TI-AOL }\end{array}$} & \multicolumn{6}{|c|}{ Variables } \\
\hline & & \multicolumn{2}{|c|}{ Height (cm) } & \multicolumn{2}{|c|}{ Number of flowers } & \multicolumn{2}{|c|}{ Number of fruits } \\
\hline & & $81,61 \pm$ & $1.68^{\wedge}$ & $1,40 \pm$ & $0,31^{\wedge}$ & $0,17 \pm$ & $0,20^{\wedge}$ \\
\hline & T2-NQ & $71,31 \pm$ & $1.62^{B}$ & $1.94 \pm$ & $0,30^{A}$ & $0.50 \pm$ & $0,20^{\wedge}$ \\
\hline & T3-CONTROL & $76,13 \pm$ & $1.62^{A B}$ & $2.19 \pm$ & $0.30^{A}$ & $0.75 \pm$ & $0.20^{A}$ \\
\hline \multirow[t]{3}{*}{ Week 2} & T1-AOL & $98.63 \pm$ & $2.89^{A}$ & $2.13 \pm$ & $0.38^{A}$ & $0.44 \pm$ & $0.23^{8}$ \\
\hline & T2-NQ & $85.56 \pm$ & $2.80^{\mathrm{B}}$ & $3.00 \pm$ & $0.36^{\mathrm{A}}$ & $1,06 \pm$ & $0,22^{\mathrm{AB}}$ \\
\hline & T3-CONTROL & $92,06 \pm$ & $2.80^{\mathrm{AB}}$ & $2,88 \pm$ & $0,36^{A}$ & $1,38 \pm$ & $0,22^{A}$ \\
\hline \multirow[t]{3}{*}{ Week 3} & TI-AOL & $105.62 \pm$ & $3,39^{\wedge}$ & $1.71 \pm$ & $0.51^{\wedge}$ & $1.37 \pm$ & $0.23^{\wedge}$ \\
\hline & T2-NQ & $92.38 \pm$ & $3.28^{B}$ & $2.81 \pm$ & $0.50^{A}$ & $2.13 \pm$ & $0.22^{A}$ \\
\hline & T3-CONTROL & $97.19 \pm$ & $3,28 A B$ & $2,50 \pm$ & $0.50^{A}$ & $1,81 \pm$ & $0,22^{A}$ \\
\hline \multirow[t]{3}{*}{ Week 4} & TI-AOL & $112,55 \pm$ & $3,66^{A}$ & $2,14 \pm$ & $0,35^{A}$ & $2,42 \pm$ & $0.25^{A B}$ \\
\hline & $\mathrm{T} 2-\mathrm{NQ}$ & $96.31 \pm$ & $3.54^{\mathrm{B}}$ & $2,56 \pm$ & $0.34^{A}$ & $3,13 \pm$ & $0.24^{A}$ \\
\hline & T3-CONTROL & $100.69 \pm$ & $3,54^{A B}$ & $2,38 \pm$ & $0.34^{A}$ & $2.19 \pm$ & $0.24^{B}$ \\
\hline \multirow[t]{3}{*}{ Week 5} & TI-AOL & $120.67 \pm$ & $3,87^{\wedge}$ & $1.35 \pm$ & $0,34^{A}$ & $3.36 \pm$ & $0,36^{A}$ \\
\hline & T2-NQ & $99.25 \pm$ & $3,74^{\mathrm{B}}$ & $1.06 \pm$ & $0,33^{A}$ & $3,75 \pm$ & $0.35^{A}$ \\
\hline & T3-CONTROL & $103,63 \pm$ & $3,74^{B}$ & $1.88 \pm$ & $0,33^{\mathrm{A}}$ & $2,63 \pm$ & $0,35^{A}$ \\
\hline \multirow[t]{3}{*}{ Week 6} & T1-AOL & $127,44 \pm$ & $4.07^{\mathrm{A}}$ & $1,69 \pm$ & $0,36^{\mathrm{A}}$ & $3,63 \pm$ & $0.38^{A}$ \\
\hline & T2-NQ & $104.88=$ & $3,93^{\text {B }}$ & $0.63 \pm$ & $0,35^{A}$ & $4.25 \pm$ & $0.37^{A}$ \\
\hline & T3-CONTROL & $109.00=$ & $3.93^{\mathrm{B}}$ & $1.31 \pm$ & $0.35^{A}$ & $3.13 \pm$ & $0,37^{A}$ \\
\hline \multicolumn{8}{|c|}{ Different letters in the same row indicate statistically significant differences according to Tukey test $(p<0,05): \pm$} \\
\hline
\end{tabular}

Table 2. Evaluation of A. oligosporus C-2197 on some physiological and agronomic traits of tomato (Solanum lycopersicum) plants hybrid ABM 135

\section{Discussion and Conclusions}

In the present study, laboratory, greenhouse, and field tests were conducted to assess the activity of A. oligosporus C-2197 as a biocontrol for Meloidogyne spp. The in vitro tests showed that A. oligosporus C-2197 grew differently depending on the type of medium used, similar to previous reports ${ }^{40,41}$. Our results are also consistent with previous work on the predatory activity of $A$. oligosporus controlling second instar juveniles of Meloidogyne spp. This fungus specializes in the formation of capture nets and demonstrates the ability to attract nematodes ${ }^{42-45}$ and the production of toxins that paralyze the movement of juveniles ${ }^{46}$.

Greenhouse tests confirmed the control activity of A. oligosporus C-2197 on the nematode population studied. This strain also showed growth-promoting activity for root development and leaf area. These data coincide with previous findings also reporting growing stimulus of plants after been treated with A. oligosporus, increasing production on tomato, rice, and carrot crops ${ }^{23,34,47-49}$. Laboratory results showed that $A$. oligosporus C-2197 could develop well in substrates with high carbon and nitrogen ratios related to its saprophytic lifestyle, a necessary feature to establish in the soil outperform other saprophytic competitors ${ }^{50,51}$. This characteristic facilitates the search for cheap substrates that can be implemented for massive scale production of a commercial product based on this strain $^{52}$.

In the present study, the application of A. oligosporus to the soil did not significantly affect nematode populations. More extensive field trials with A. oligosporus C-2197 are needed, as the "Bio-cover" may have affected the control of the fungus' efficacy. Evidence shows the efficacy of $A$. oligosporus to trap nematodes can vary when conditions are too variable $e^{53-55}$.

In conclusion, it was demonstrated that $A$. oligosporus 
10. Mwageni W, Blok V, Daudi A, Bala G, Davies K, Netscher C, et al. The importance of tropical root-knot nematodes (Meloidogyne spp.) and factors affecting the utility of Pasteuria penetrans as a biocontrol agent. Nematology. 2000 Jan 1;2(8):823-45.

11. Giné A, López区Gómez M, Vela MD, Ornat C, Talavera M, Verdejo® Lucas $S$, et al. Thermal requirements and population dynamics of root-knot nematodes on cucumber and yield losses under protected cultivation. Plant Pathology. 2014;63(6):1446-53.

12. Ali N, Tavoillot J, Chapuis E, Mateille T. Trend to explain the distribution of root-knot nematodes Meloidogyne spp. associated with olive trees in Morocco. Agriculture, Ecosystems \& Environment. 2016 Jun 1;225:22-32.

13. Karssen G, Wesemael WML, Moens M. Root-knot nematodes. In: Perry RN, Moens M, editors. Plant Nematology. Wallingford, UK: CABI Publishing; 2013. p. 73-108.

14. Lu W, Wang X, Wang F, Liu J. Fine root capture and phenotypic analysis for tomato infected with Meloidogyne incognita. Computers and Electronics in Agriculture. 2020 Jun 1;173:105455.

15. López-Gómez M, Flor-Peregrín E, Talavera M, Sorribas FJ, Verdejo-Lucas S. Population dynamics of Meloidogyne javanica and its relationship with the leaf chlorophyll content in zucchini. Crop Protection. 2015 Apr 1;70:8-14.

16. Fráguas RM, Costa VA, Terra WC, Aguiar AP, Martins SJ, Campos VP, et al. Toxicities of 4,5-Dihydroisoxazoles against root-knot nematodes and in silico studies of their modes of action. J Agric Food Chem. 2020 Jan 15;68(2):523-9.

17. Prasad BDN, Subramanyam B, Lakshmipathi RN, Ansari RA, Rizvi $R$, Sumbul $A$, et al. Utilization of beneficial microorganisms in sustainable control of phytonematodes. In: Ansari RA, Rizvi R, Mahmood I, editors. Management of phytonematodes: Recent advances and future challenges [Internet]. Singapore: Springer; 2020 [cited 2020 Sep 8]. p. 317-37. Available from: https://doi. org/10.1007/978-981-15-4087-5_14

18. Souza GDS, Costa LCA da, Maciel AC, Reis FDV, Pamplona Y de AP. Presence of pesticides in atmosphere and risk to human health: a discussion for the Environmental Surveillance. Cien Saude Colet. 2017 Oct;22(10):3269-80.

19. Vrijheid M, Casas M, Gascon M, Valvi D, Nieuwenhuijsen M. Environmental pollutants and child health-A review of recent concerns. International Journal of Hygiene and Environmental Health. 2016 Jul 1;219(4):331-42.

20.FAO. Food and agriculture organization of the United Nations. [Internet]. Codex Pestic Residues in Food Online Database. 2019 [cited 2020 Nov 11]. Available from: http://www.fao.org/ fao-who-codexalimentarius/codex-texts/dbs/pestres/en/

21. Moosavi MR. Efficacy of microbial biocontrol agents in integration with other managing methods against phytoparasitic nematodes. In: Ansari RA, Rizvi R, Mahmood I, editors. Management of phytonematodes: Recent advances and future challenges [Internet]. Singapore: Springer; 2020 [cited 2020 Sep 8]. p. 229-58. Available from: https://doi.org/10.1007/978-981-15-4087-5_10

22. Hahn MH, May De Mio LL, Kuhn OJ, Duarte H da SS. Nematophagous mushrooms can be an alternative to control Meloidogyne javanica. Biological Control. 2019 Nov 1;138:104024.

23. Peiris PUS, Li Y, Brown P, Xu C. Fungal biocontrol against Meloidogyne spp. in agricultural crops: A systematic review and meta-analysis. Biological Control. 2020 May 1;144:104235.

24. Jiang X, Xiang M, Liu X. Nematode-Trapping Fungi. Microbiol Spectr. 2017:5(1).

25. Vidal-Diez de Ulzurrun G, Hsueh Y-P. Predator-prey interactions of nematode-trapping fungi and nematodes: both sides of the coin. Appl Microbiol Biotechnol. 2018 May;102(9):3939-49.

26. Kumar D, Maurya N, Kumar P, Singh H, Addy SK. Assessment of germination and carnivorous activities of a nematode-trapping fungus Arthrobotrys dactyloides in fungistatic and fungicidal soil environment. Biological Control. 2015 Mar 1;82:76-85.

27. Wang B-L, Chen Y-H, He J-N, Xue H-X, Yan N, Zeng Z-J, et al. Integrated metabolomics and morphogenesis reveal volatile signaling of the nematode-trapping fungus Arthrobotrys oligospora. Drake HL, editor. Appl Environ Microbiol. 2018 May 1;84(9):e02749-17.
28. Yang Y, Yang E, An Z, Liu X. Evolution of nematode-trapping cells of predatory fungi of the Orbiliaceae based on evidence from rRNA-encoding DNA and multiprotein sequences. Proc Natl Acad Sci USA. 2007 May 15;104(20):8379-84.

29. Su H, Zhao Y, Zhou J, Feng H, Jiang D, Zhang K-Q, et al. Trapping devices of nematode-trapping fungi: formation, evolution, and genomic perspectives. Biol Rev Camb Philos Soc. 2017 Feb;92(1):357-68.

30. Hsueh Y-P, Gronquist MR, Schwarz EM, Nath RD, Lee C-H, Gharib $\mathrm{S}$, et al. Nematophagous fungus Arthrobotrys oligospora mimics olfactory cues of sex and food to lure its nematode prey. Hobert O, editor. eLife. 2017 Jan 18;6:e20023.

31. Kumar N, Singh RK, Singh KP. Occurrence and colonization of nematophagous fungi in different substrates, agricultural soils and root galls. Archives of Phytopathology and Plant Protection. 2011 Jul 1;44(12):1182-95.

32. Niu X-M, Zhang K-Q. Arthrobotrys oligospora: a model organism for understanding the interaction between fungi and nematodes. Mycology. 2011 Jun 1;2(2):59-78.

33. Hiep NV, Ha NT, Thuy TTT, Toan PV. Isolation and selection of Arthrobotrys nematophagous fungi to control the nematodes on coffee and black pepper plants in Vietnam. Archives of Phytopathology and Plant Protection. 2019 May 9;52(7-8):825-43.

34. Singh UB, Sahu A, Sahu N, Singh RK, Renu S, Singh DP, et al. Arthrobotrys oligospora-mediated biological control of diseases of tomato (Lycopersicon esculentum Mill.) caused by Meloidogyne incognita and Rhizoctonia solani. Journal of Applied Microbiology. 2013;114(1):196-208.

35. Mostafanezhad H, Sahebani N, Zarghani SN. Control of root-knot nematode (Meloidogyne javanica) with combination of Arthrobotrys oligospora and salicylic acid and study of some plant defense responses. Biocontrol Science and Technology. 2014 Feb 1;24(2):203-15.

36. Ellis MB. Dematiaceous Hyphomycetes. Kew, Commonwealth Mycological Institute.; 1971. 608 p.

37. Seifert K, Morgan-Jones G, Gams W, Kendrick B. The Genera of Hyphomycetes. CBS-KNAW Fungal Biodiversity Centre; 2011. $997 \mathrm{p}$.

38. Duddington $\mathrm{CL}$. Notes on the technique of handling predacious fungi. Transactions of the British Mycological Society. 1955 Jun 1;38(2):97-103.

39. Bridge J, Page SLJ. Estimation of root-knot nematode infestation levels on roots using a rating chart. Tropical Pest Management. 1980 Sep 1;26(3):296-8.

40.Belder $E$, Jansen $E$. The influence of temperature, nutrition, light and the growth time of the mycelium on capture and infection of Meloidogyne hapla by Arthrobotrys oligospora. Fundamental and Applied Nematology. 1994;17(1):57-66.

41.Cardoso ER, Assis LC, Nahas E. Nutrição e crescimento do fungo nematófago Arthrobotrys oligospora. Summa Phytopathologica. 2009 Dec;35(4):267-72.

42. Jansson H-B, Nordbring-Hertz B. Attraction of nematodes to living mycelium of nematophagous fungi. Microbiology,. 1979;112(1):89-93.

43. Saxena G, Dayal R, Mukerji KG. Interaction of nematodes with nematophagus fungi: induction of trap formation, attraction and detection of attractants. FEMS Microbiol Ecol. 1987 Dec 1;3(6):319-27.

44. Yang J, Wang L, Ji X, Feng Y, Li X, Zou C, et al. Genomic and proteomic analyses of the fungus Arthrobotrys oligospora provide insights into nematode-trap formation. PLOS Pathogens. 2011 Sep 1;7(9):e1002179.

45. Hussain M, Maňasová M, Zouhar M, Ryšánek P. Comparative virulence assessment of different nematophagous fungi and chemicals against northern root-knot nematodes, Meloidogyne hapla, on carrots. PJZ. 2019;52(1).

46. Bird J, Herd RP. In vitro assessment of two species of nematophagous fungi (Arthrobotrys oligospora and Arthrobotrys flagrans) to control the development of infective cyathostome larvae from naturally infected horses. Veterinary Parasitology. 1995 Jan 1;56(1):181-7. 
47. Gray NF. Nematophagous fungi with particular reference to their ecology. Biological Reviews. 1987;62(3):245-304.

48. Singh UB, Sahu A, Singh RK, Singh DP, Meena KK, Srivastava JS, et al. Evaluation of biocontrol potential of Arthrobotrys oligospora against Meloidogyne graminicola and Rhizoctonia solani in Rice (Oryza sativa L.). 2012;60(3):262-70.

49. Hussain M, Zouhar M, Rysanek P. Potential of some nematophagous fungi against Meloidogyne hapla infection in Czech Republic. PJZ. 2016 Oct 2:49(1):35-43.

50. Jaffee BA. Wood, nematodes, and the nematode-trapping fungus Arthrobotrys oligospora. Soil Biology and Biochemistry. $2004 \mathrm{Jul}$ 1;36(7):1171-8.

51. Nguyen V, Bastow J, Jaffee B, Strong D. Response of nematode-trapping fungi to organic substrates in a coastal grassland soil. Mycol Res. 2007 May 13;111(Pt 7):856-62.
52. Lee J-K, Kim D-G, Lee S-B, Nutritional requirements and mass production of nematode-trapping fungus, Arthrobotrys oligospora. Journal of Asia-Pacific Entomology. 2004 Oct 1;7(3):325-9.

53. Galper S, Eden LM, Stirling GR, Smith LJ. Simple screening methods for assessing the predacious activity of nematode-trapping fungi. Nematologica. 1995 Jan 1;41(1-4):130-40.

54. Jaffee BA. Correlations between most probable number and activity of nematode-trapping fungi. Phytopathology. 2003 Dec;93(12):1599-605.

55. Jaffee BA. Do organic amendments enhance the nematode-trapping fungi Dactylellina haptotyla and Arthrobotrys oligospora? J Nematol. 2004 Sep;36(3):267-75.

Received: 2 december 2020

Accepted: 25 january 2021

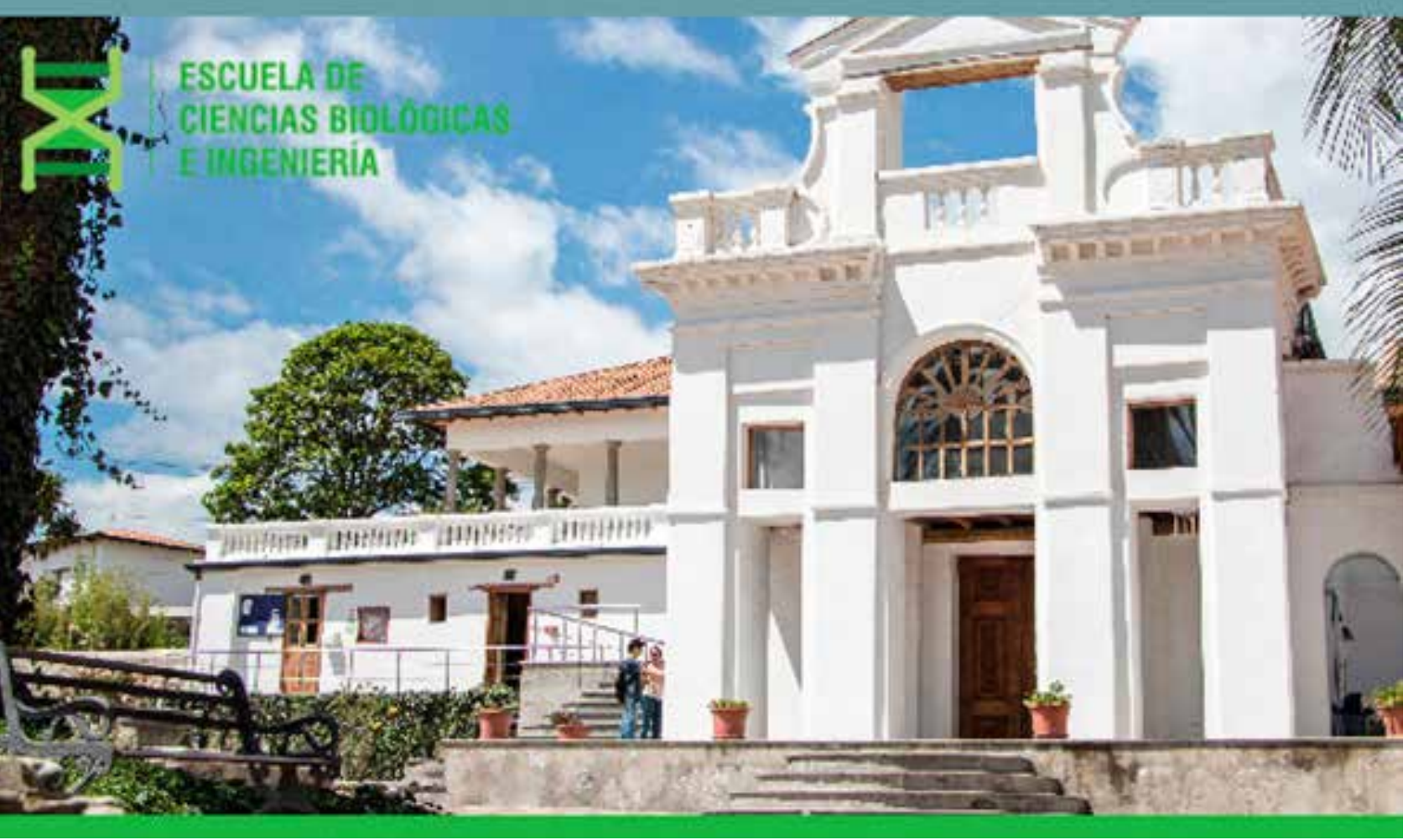

